\title{
Risk of Down syndrome in duodenal atresia and atrioventricular septal defect: Is there an ethnic difference?
}

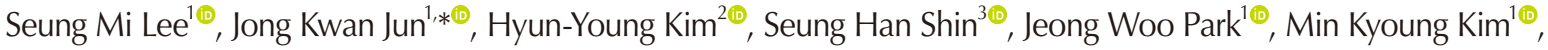 \\ Chan-Wook Park ${ }^{1 \oplus}$, and Joong Shin Park ${ }^{1 \oplus}$ \\ 'Department of Obstetrics and Gynecology, Seoul National University College of Medicine, Seoul, Korea \\ ${ }^{2}$ Department of Pediatric Surgery, Seoul National University College of Medicine, Seoul, Korea \\ ${ }^{3}$ Department of Pediatrics, Seoul National University College of Medicine, Seoul, Korea
}

\begin{abstract}
Purpose: Duodenal atresia (DA) and atrioventricular septal defect (AVSD) are well known ultrasonographic findings associated with Down syndrome. The risk of Down syndrome in fetuses with these anomalies has been reported as 30\% to $40 \%$. However, on the basis of our clinical experience, the risk of Down syndrome of DA may be lower in Korean population. To clarify this issue, we compared the risk of Down syndrome between cases with DA and AVSD.

Materials and Methods: The study population consisted of neonates who were confirmed as DA or AVSD by postnatal diagnosis. Postnatal diagnosis was made by surgery, postnatal echocardiography, or autopsy. Medical record was reviewed retrospectively.

Results: A total of 213 neonates with DA or AVSD were included: 67 cases with DA and 146 cases with AVSD. The risk of Down syndrome was 4.5\% (3/67) in DA vs. 29.5\% (43/146) in AVSD. When confining analysis to those whose karyotyping were not performed during antenatal period, the risk of Down syndrome were 7.9\% (3/38) in DA and 35.4\% (35/99) in AVSD. Conclusion: The risk of Down syndrome in cases with DA was much lower in Korean population than previously reported risk in the literature. The significance of some antenatal sonographic markers for Down syndrome may be different according to ethnicity.
\end{abstract}

Key words: Duodenal obstruction, Atrioventricular septal defect, Down syndrome, Aneuploidy.

\section{Introduction}

Down syndrome is estimated to be 1 to 2 per 1,000 live births [1-3], usually resulting from maternal nondisjunction of chromosome 21 [4]. As Down syndrome is the most common trisomy and imposes a heavy burden on the family and the society, it has been the main focus of prenatal screening and diagnosis. The screening modalities include measurement of nuchal translucency, maternal serum screening test, cell-free DNA screening, and ultrasonographic detection of structural anomalies. Associated major anomalies of Down syndrome include central nervous system anomalies (ventriculomegaly or hydrocephalus),

Received: 19 May 2020, Revised: 17 June 2020, Accepted: 17 June 2020, Published: 30 June 2020

*Corresponding author: Jong Kwan Jun, M.D., Ph.D. (D) https://orcid.org/0000-0002-0242-1736

Department of Obstetrics and Gynecology, Seoul National University College of Medicine, 103 Daehak-ro, Jongno-gu, Seoul 03080, Korea.

Tel: +82-2-2072-3744, Fax: +82-2-762-3599, E-mail: jhs0927@snu.ac.kr

Conflict of interest: The authors declare that they do not have any conflicts of interest.

(ㄷ) This is an open-access article distributed under the terms of the Creative Commons Attribution Non-Commercial License (http://creativecommons.org/licenses/by-nc/4.0/) which permits unrestricted non-commercial use, distribution, and reproduction in any medium, provided the original work is properly cited.

(c) Copyright 2020 by the Korean Society of Medical Genetics and Genomics 
cardiac anomalies, cystic hygroma, gastrointestinal anomalies (duodenal atresia [DA], esophageal atresia, tracheoesophageal fistula, or omphalocele). Some ultrasound markers such as hyperechoic bowel, pyelectasia, short long bone, or echogenic intracardiac foci can also increase the possibility of Down syndrome. Among these anomalies, cardiac defect, especially atrioventricular septal defect (AVSD), and DA are the most common ones [4].

If DA or AVSD are detected in prenatal ultrasonography, the risk of Down syndrome has been reported as 30\% to 40\% [5-7]. However, on the basis of our clinical experience, the risk of Down syndrome in DA may be lower in Korean population. To clarify this issue, we compared the risk of Down syndrome between cases with DA and those with AVSD.

\section{Materials and Methods}

\section{Study design}

In this retrospective cohort study, we included neonates who were confirmed as DA or AVSD by postnatal diagnosis at the Seoul National University Hospital between January 1999 and March 2016. The postnatal diagnosis was confirmed by surgery, postnatal echocardiography, or autopsy. The Institutional Review Board of the Seoul National University Hospital approved the clinical information for research purposes.

\section{Clinical characteristics and chromosomal analysis}

The clinical characteristics, type of associated congenital malformations, and the result of karyotyping were retrieved by review of medical record. In cases whose diagnosis of DA or AVSD was made in antenatal period, the decision to do fetal karyotyping was usually made by antenatal counseling. In neonates whose parents rejected to perform fetal karyotyping, or in neonates whose diagnosis of DA or AVSD was initially made in postnatal period, the decision for chromosomal analysis after birth was made according to the attending pediatrician. Neonates who died in uterus, or who died shortly after delivery and whose parents rejected the chromosome study and thus could not be evaluated with respect to the possibility of aneuploidy were excluded from analysis.

\section{Statistical analysis}

The results were analyzed using IBM SPSS Statistics for Windows version 25.0 (IBM Corp., Armonk, NY, USA). Proportions between groups were compared with chi-square test. A $P$-value $<0.05$ was considered significant.

\section{Results}

During the study period, a total of 238 neonates were suspected as DA or AVSD. Among these neonates, cases in which

Table 1. Characteristics of the study population

\begin{tabular}{lccc}
\hline \multicolumn{1}{c}{ Characteristic } & $\begin{array}{c}\text { Duodenal atresia } \\
(\mathrm{n}=67)\end{array}$ & $\begin{array}{c}\text { Atrioventricular septal defect } \\
(\mathrm{n}=146)\end{array}$ & $\mathrm{P}$-value \\
\hline Sex (male) & $34(50.7)$ & $60(41.1)$ & $<$ NS \\
Preterm delivery & $16(23.9)$ & $10 / 130(7.7)$ & $\mathrm{NS}$ \\
\hline Termination & $0(0.0)$ & $2(1.4)$ & 0.005 \\
Associated anomaly & $18(26.9)$ & $57(39.0)$ & $\mathrm{NS}$ \\
Central nervous system & $0(0.0)$ & $1(0.7)$ & $\mathrm{NS}$ \\
Vertebral & $1(1.5)$ & $1(0.7)$ & $<0.05$ \\
Ear, face, and neck & $2(3.0)$ & $0(0.0)$ & $<0.001$ \\
Cardiovascular & $9(13.4)$ & $55(37.7)$ & $\mathrm{NS}$ \\
Pulmonary & $1(1.5)$ & $1(0.7)$ & $<0.005$ \\
Gastrointestinal & $7(10.4)$ & $2(1.4)$ & $<0.005$ \\
Genitourinary & $4(6.0)$ & $0(0.0)$ & $\mathrm{NS}$ \\
Extremities & $1(1.5)$ & $1(0.7)$ & 0.058 \\
Others & $3(4.5)$ & $1(0.7)$ & $<0.001$ \\
Syndrome & $0(0.0)$ & $36(24.7)$ & $<0.001$ \\
Heterotaxy syndrome & $0(0.0)$ & $33(22.6)$ & $<0.05$ \\
Corrective surgery & $66(98.5)$ & $128(87.7)$ & $<0.001$ \\
Death & $1(1.5)$ & $31(21.2)$ & \\
\hline
\end{tabular}

Values are presented as number (\%).

NS, not significant. 
postnatal final diagnosis was not DA or AVSD as suspected in antenatal period $(n=17)$, case in which the medical record was not available $(n=1)$, and cases in which the neonates had both of DA and AVSD ( $n=2)$ were excluded. In the remaining 218 neonates, 3 cases in which the fetus died in utero and the chromosomal result was not available because of culture failure, 1 case in which the neonates died shortly after delivery without any work up, and 1 case in which the parents rejected all kinds of work up studies were excluded from the analysis.

A total of 213 cases comprised of 67 cases of DA and 146 cases of AVSD were included in the analysis. Table 1 shows the clinical characteristics of the study population. The sex ratio and the proportion of termination of pregnancy were not different between the two groups of cases. However, the proportion of preterm delivery, rate of surgery, and the survival were different between the two groups.

Table 2. Risk of Down syndrome

\begin{tabular}{cccc}
\hline Characteristics & $\begin{array}{c}\text { Duodenal } \\
\text { atresia }\end{array}$ & $\begin{array}{c}\text { Atrioventricular } \\
\text { septal defect }\end{array}$ & $P$-value \\
\hline In total neonates & 67 & 146 & \\
Down syndrome & $3(4.5)$ & $43(29.5)$ & $<0.001$ \\
In postnatal neonates & 38 & 99 & \\
Down syndrome & $3(7.9)$ & $35(35.4)$ & $<0.005$ \\
\hline
\end{tabular}

Values are presented as number only or number (\%).

${ }^{\text {a }}$ ostnatal patients means those whose karyotyping were not performed during antenatal period.
Table 2 demonstrates the risk of Down syndrome in the two groups of cases. The risks of Down syndrome were 4.5\% (3/67) in DA vs. 29.5\% (43/146) in AVSD.

We also compared the risk of Down syndrome between the two groups, after confining analysis only to those whose karyotyping were not performed during antenatal period. The risks of Down syndrome were 7.9\% (3/38) in DA and 35.4\% (35/99) in AVSD.

\section{Discussion}

The principal findings of the study were 1) the risk of Down syndrome was lower in cases with DA than previously reported; 2) The risk of Down syndrome remained lower even when confining analysis to those whose karyotyping were not performed during antenatal period.

Table 3 shows the reported incidence of Down syndrome in DA or AVSD ranging around 28\% to 51\%, except the report from Taiwan with the incidence of 13\%. The risks of Down syndrome were $5.4 \%(3 / 56)$ in DA in the current study [5-16]. Why is the risk of Down syndrome in Korean population lower than previously reported? One possible explanation might be ethnic difference in Korean or some Asian population such as Taiwanese from other ethnic groups. Actually in the current study population, the risk of Down syndromes in cases with AVSD was 30\%, which was comparable to that in previous studies $[6,8,9]$. How-

Table 3. Reported incidence of Down syndrome in duodenal atresia or atrioventricular septal defect

\begin{tabular}{|c|c|c|c|}
\hline Author & $\mathrm{n}$ & Incidence of Down syndrome & Incidence of aneuploidy \\
\hline \multicolumn{4}{|l|}{ Duodenal atresia } \\
\hline Singh et al. 2004 [5] (UK) & 79 & $28(35.4)$ & \\
\hline Keckler et al. 2008 [7] (USA) & 94 & $39(41.5)$ & \\
\hline $\begin{array}{l}\text { Mustafawi and Hassan, } 2008 \text { [10] } \\
\text { (United Arab Emirates) }\end{array}$ & 77 & $36(46.8)$ & \\
\hline Choudhry et al. 2009 [11] (UK) & 61 & $28(45.9)$ & \\
\hline Tsai et al. 2010 [12] (Taiwan) & 30 & $4(13.3)$ & \\
\hline Current study & 56 & $3(5.4)$ & $3(5.4)$ \\
\hline \multicolumn{4}{|l|}{ Atrioventricular septal defect } \\
\hline Gembruch et al. 1991 [13] (Germany) & 14 & & $8(57.1)$ \\
\hline Delisle et al. 1999 [14] (Canada) & 42 & $19(45.2)$ & $22(52.4)$ \\
\hline Fesslova et al. 2002 [6] (Italy) & 82 & $23(28.0)$ & $33(40.2)$ \\
\hline Paladini et al. 2000 [9] (Italy) & 21 & $9(42.9)$ & $10(47.6)$ \\
\hline Huggon et al. 2000 [8] (UK) & 301 & 86/218 (39.4) & 107/218 (49.1) \\
\hline Friedberg et al. 2007 [15] (USA) & 20 & & $6(30.0)$ \\
\hline Berg et al. 2009 [16] (Germany) & 246 & $77(31.3)$ & $129(52.4)$ \\
\hline Current study & 138 & $42(30.4)$ & $44(31.9)$ \\
\hline
\end{tabular}

Values are presented as number only or number (\%).

AVSD, atrioventricular septal defect. 
ever, the risk of Down syndrome in DA was quite lower than that in previous reports, which is about $30 \%[5,7,10,17]$.

Although DA has been thought to result from developmental failure of intestinal luminal canalization [18], the exact pathogenesis of DA remains incompletely understood. Previous studies have proposed ischemia or vascular accident as the possible etiology $[19,20]$. However, several evidences indicate the possibility of genetic influence on the pathogenesis. Cragan et al. [21] showed higher incidence of DA in twins than in singleton, and Gahukamble et al. $[22,23]$ reported cases of DA occurring in two siblings and a pair of monozygotic twins. The suggestion regarding the possibility of genetic impact on the development of DA may be attributed to the lower incidence of Down syndrome in cases of DA in Korean (Asian) population. Most papers reporting higher incidences of Down syndrome in DA were originated from the data of Caucasian (Europe or North America, Table 3). Other racial/ethnic data from Asian group will help us to determine the ethnic/genetic impact on the development of DA. Indeed, several types of anomalies showed racial/ethnic differences, such as bicuspic aortic valve, esophageal atresia, type of isomerism, and other congenital anomalies [24-26].

In addition, the incidence of DA itself might be different among races or ethnicities. In the report of international clearinghouse for birth defects surveillance and research (ICBDSR), the rate of congenital small intestine atresia in Japan was $8.01 / 10,000$ which was about three times higher than that in western countries (2.71/10,000 in Australia, 1.57/10,000 in Canada, 1.78/10,000 in Chile, 0.73/10,000 in France, 1.27/10,000 in Germany, 1.11/10,000 in United Kingdom, and 2.36/10,000 in United States) [27]. This relatively higher incidence of DA might be contributed to the different frequency of Down syndrome in DA. In other words, although DA associated with Down syndrome in Korean population is similar to that in other ethnic groups, proportion of Down syndrome in DA is lower because the incidence of DA is high.

Some may argue that the retrospective nature of the current study may predispose to the selection bias of study population. It may be that DA is easy to detect in antenatal period, resulting in increased chance of pregnancy termination, although it is usually diagnosed late 2 nd or early 3 rd trimester. However the different risk of Down syndrome between DA and AVSD in the current study remained significant even when confining analysis to those whose karyotyping were not performed during antenatal period.

Another possibility is the early termination of Down syndrome with DA. In Korea, the prenatal risk assessment for chromosomal anomaly is prevalent, and diagnostic test is provided in cases with positive result of screening test. Therefore, early termination according to the prenatal risk assessment for Down syndrome might be performed, before the sign of DA is apparent in ultrasound. However, only 3.9\% of Down syndrome has DA, even though DA is an important ultrasonographic finding to suggest Down syndrome [28]. Therefore, early termination of Down syndrome with DA is still possible, but its impact is marginal.

The findings of the current study that the risk of Down syndrome was lower in Korean cases with DA than previous reported should be interpreted in two points of view. First, the different genetic risk of Down syndrome according to ethnicity should be taken into the consideration on the prenatal counseling in DA. This different risk can be adjusted in the diagnostic decision strategy for detection of Down syndrome. Second, other ultrasound markers for Down syndrome might need reevaluation in the risk of Down syndrome, because there is also a possibility of different risk of Down syndrome in other ultrasound abnormalities.

In conclusion, the risk of Down syndrome in cases with DA was only one-sixth to one-fourth of the risk previously reported in the literature. The significance of some antenatal sonographic markers for Down syndrome may be different according to ethnic groups.

\section{Acknowledgements}

This study was supported by SNUCM (Seoul National University College of Medicine) Foundation Research Program (80020140525).

\section{References}

1. Baird PA, Sadovnick AD. Causes of death to age 30 in Down syndrome. Am J Hum Genet 1988;43:239-48.

2. Frid $C$, Drott $P$, Lundell $B$, Rasmussen $F$, Annerén G. Mortality in Down's syndrome in relation to congenital malformations. J Intellect Disabil Res 1999;43(Pt 3):234-41.

3. Weijerman $M E$, van Furth $A M$, Vonk Noordegraaf $A$, van Wouwe JP, Broers CJ, Gemke RJ. Prevalence, neonatal characteristics, and first-year mortality of Down syndrome: a national study. J Pediatr 2008;152:15-9.

4. Cunningham FG, Leveno KJ, Bloom SL, Hauth JC, Rouse DJ, Spong CY. Preterm birth. In: Cunningham FG, Leveno KL, Bloom SL, Hauth JC, Rouse DJ, Spong CY, eds. Williams obstetrics. 23rd ed. New York: 
McGraw-Hill; 2010;814-7.

5. Singh MV, Richards C, Bowen JC. Does Down syndrome affect the outcome of congenital duodenal obstruction? Pediatr Surg Int 2004;20:586-9.

6. Fesslova V, Villa L, Nava S, Boschetto C, Redaelli C, Mannarino S. Spectrum and outcome of atrioventricular septal defect in fetal life. Cardiol Young 2002;12:18-26.

7. Keckler SJ, St Peter SD, Spilde TL, Ostlie DJ, Snyder CL. The influence of trisomy 21 on the incidence and severity of congenital heart defects in patients with duodenal atresia. Pediatr Surg Int 2008;24:921-3.

8. Huggon IC, Cook AC, Smeeton NC, Magee AG, Sharland GK. Atrioventricular septal defects diagnosed in fetal life: associated cardiac and extra-cardiac abnormalities and outcome. J Am Coll Cardiol 2000;36:593-601.

9. Paladini D, Tartaglione A, Agangi A, Teodoro A, Forleo F, Borghese A, et al. The association between congenital heart disease and Down syndrome in prenatal life. Ultrasound Obstet Gynecol 2000;15:104-8.

10. Mustafawi AR, Hassan ME. Congenital duodenal obstruction in children: a decade's experience. Eur J Pediatr Surg 2008;18:93-7.

11. Choudhry MS, Rahman N, Boyd P, Lakhoo K. Duodenal atresia: associated anomalies, prenatal diagnosis and outcome. Pediatr Surg Int 2009;25:727-30.

12. Tsai LY, Hsieh WS, Chen CY, Chou HC, Tsao PN, Hsu WM. Distinct clinical characteristics of patients with congenital duodenal obstruction in a medical center in Taiwan. Pediatr Neonatol 2010;51:343-6.

13. Gembruch U, Knöpfle G, Chatterjee M, Bald R, Redel DA, Födisch HJ, et al. Prenatal diagnosis of atrioventricular canal malformations with up-to-date echocardiographic technology: report of 14 cases. Am Heart J 1991;121:1489-97.

14. Delisle MF, Sandor GG, Tessier F, Farquharson DF. Outcome of fetuses diagnosed with atrioventricular septal defect. Obstet Gynecol 1999:94(5 Pt 1):763-7.

15. Friedberg MK, Kim N, Silverman NH. Atrioventricular septal defect recently diagnosed by fetal echocardiography: echocardiographic features, associated anomalies, and outcomes. Congenit Heart Dis 2007:2:110-4.

16. Berg C, Kaiser C, Bender F, Geipel A, Kohl T, Axt-Fliedner R, et al.
Atrioventricular septal defect in the fetus--associated conditions and outcome in 246 cases. Ultraschall Med 2009;30:25-32.

17. Shawis $R$, Antao B. Prenatal bowel dilatation and the subsequent postnatal management. Early Hum Dev 2006;82:297-303.

18. Cohen-Overbeek TE, Grijseels EW, Niemeijer ND, Hop WC, Wladimiroff JW, Tibboel D. Isolated or non-isolated duodenal obstruction: perinatal outcome following prenatal or postnatal diagnosis. Ultrasound Obstet Gynecol 2008;32:784-92.

19. Louw JH, Barnard CN. Congenital intestinal atresia; observations on its origin. Lancet 1955;269:1065-7.

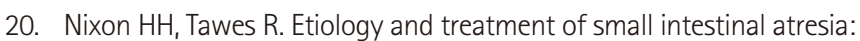
analysis of a series of 127 jejunoileal atresias and comparison with 62 duodenal atresias. Surgery 1971;69:41-51.

21. Cragan JD, Martin ML, Waters GD, Khoury MJ. Increased risk of small intestinal atresia among twins in the United States. Arch Pediatr Adolesc Med 1994;148:733-9.

22. Gahukamble DB, Khamage AS, Shaheen AQ. Duodenal atresia: its occurrence in siblings. J Pediatr Surg 1994;29:1599-600.

23. Gahukamble DB, Adnan AR, Al Gadi M. Distal foregut atresias in consecutive siblings and twins in the same family. Pediatr Surg Int 2003;19:288-92.

24. Chandra S, Lang RM, Nicolarsen J, Gayat E, Spencer KT, Mor-Avi V, et al. Bicuspid aortic valve: inter-racial difference in frequency and aortic dimensions. JACC Cardiovasc Imaging 2012;5:981-9.

25. van Heurn LW, Cheng $W$, de Vries $B$, Saing $H$, Jansen NJ, Kootstra G, et al. Anomalies associated with oesophageal atresia in Asians and Europeans. Pediatr Surg Int 2002;18:241-3.

26. Chung CS, Myrianthopoulos NC. Factors affecting risks of congenital malformations. I. Analysis of epidemiologic factors in congenital malformations. Report from the Collaborative Perinatal Project. Birth Defects Orig Artic Ser 1975;11:1-22.

27. (ICBDSR) Icfbdsar. Annual report 2012:265.

28. Freeman SB, Torfs CP, Romitti PA, Royle MH, Druschel C, Hobbs CA, et al. Congenital gastrointestinal defects in Down syndrome: a report from the Atlanta and National Down Syndrome Projects. Clin Genet 2009;75:180-4. 